\title{
Obesity as a significant risk factor for endometrial cancer
}

\author{
Amer Suskic $^{1 *}$, Sanela Halilovic Suskic ${ }^{2}$, Dejan Opric ${ }^{3}$, Sinisa Maksimovic ${ }^{4}$
}

\author{
${ }^{1}$ Department of Obstetrics and Gynaecology, ${ }^{2}$ Department of Internal medicine, General hospital Travnik, Travnik, \\ Bosnia and Herzegovina \\ ${ }^{3}$ Department of Pathology, Medical Faculty University of Belgrade, Belgrade, Serbija \\ ${ }^{4}$ Department of Oncological surgery, Public hospital St. Vracevi, Bijeljina, Bosnia and Herzegovina
}

Received: 03 July 2016

Accepted: 05 August 2016

\section{*Correspondence:}

Dr. Amer Suskic,

E-mail: suskic@bih.net.ba

Copyright: ( the author(s), publisher and licensee Medip Academy. This is an open-access article distributed under the terms of the Creative Commons Attribution Non-Commercial License, which permits unrestricted non-commercial use, distribution, and reproduction in any medium, provided the original work is properly cited.

\begin{abstract}
Background: Endometrial cancer is the most developed countries the most common invasive neoplasms of the female reproductive system. The most frequently mentioned risk factors, which are associated with the occurrence of endometrial cancer are obesity, infertility, high blood pressure, diabetes, liver disease, hormone-active tumors of the ovary, and the use of external estrogen.

Methods: This paper deals with data of the patients treated for endometrial carcinoma in Public Hospitals in Travnik, gynecological department in the period from 01 January 2007 to 01 January 2013 the sample consisted of 90 women with endometrial carcinoma, with ages ranging from 42 to 90 years (mean of 64 years).

Results: 65 cases $(73 \%)$ were of endometrioid and $25(27 \%)$ nonendometrioid carcinoma. Obesity is an important risk factor for endometrial carcinoma, in our sample of 90 patients most of the patients was obese, and this risk factor was statistically processed and presented. Endometrioid carcinoma had $16(45 \%)$ patients with a BMI $<30 \mathrm{~kg} / \mathrm{m}^{2}$, and the Non-endometrioid carcinoma had $20(55 \%)$ patients. $38(70 \%)$ patients with a BMI> $30 \mathrm{~kg} / \mathrm{m}^{2} \mathrm{had}$ endometrioid carcinoma, and 16 patients $(30 \%)$ had Non-endometrioid carcinoma.

Conclusions: Obesity is the strongest risk factor for the development of endometrial cancer due to the mechanism of increased exposure to non-opposed estrogen. Consequently, the link between obesity and endometrial cancer is stronger in cases of tumor type 1, typical estrogen-dependent tumors.
\end{abstract}

Keywords: Endometrial cancer, Reproductive system

\section{INTRODUCTION}

Endometrial cancer is the most common invasive neoplasms of the female reproductive system in most developed countries. According to data of the American Cancer Society, 33,000 new cases a year occur in the United States. This malignancy is twice more common than cancer of the cervix or ovaries. The most frequently mentioned risk factors, which are associated with the occurrence of endometrial cancer are obesity, infertility, high blood pressure, diabetes, liver disease, hormoneactive tumors of the ovary, and the use of external estrogen, which is certainly one of the best-studied factors. Obesity is defined by the World Health
Organization as body mass index $>30 \mathrm{~kg} / \mathrm{m} 2$ (BMI> 30 $\mathrm{kg} / \mathrm{m}^{2}$ ). In obese patients with overweight from 9.5 to 23 $\mathrm{kg}$ develops three times more often endometrial cancer compared to women with normal weight, those over 23 $\mathrm{kg}$ overweight frequency of occurrence increases tenfold. The main cause is increased extra glandular conversion of androstenedione to estrone and of DHEA, particularly in the subcutaneous adipose tissue.

\section{METHODS}

In this retrospective study we present the results of 90 patients with diagnosed endometrial cancer in the period from 2007 to 2013. In Cantonal Hospital in Travnik after 
diagnostic curettage and abdominal hysterectomy. The age range was 42-90 (mean 64 years).

For each patient has formed a special questionnaire in which were written the following data: age, general condition, associated diseases (anemia, hypertension, diabetes, adiposity, other diseases), the time of onset of symptoms, makropatološki finding in the abdomen, the presence of malignant cells in the ascites, macroscopically finding of the uterus, macroscopically enlarged lymph nodes, type of surgery, tumor diameter in $\mathrm{mm}$, stage endometrial cancer, microscopic appearance, histological tumor grade.

\section{RESULTS}

The sample consisted of 90 women with endometrial cancer, aged 42- 90 years (Average 64 years). In 65 cases (73\%) was endometrioid type in 25 cases (27\%) was Non-endometrioid type of endometrial carcinoma (Figure 1 and 2).

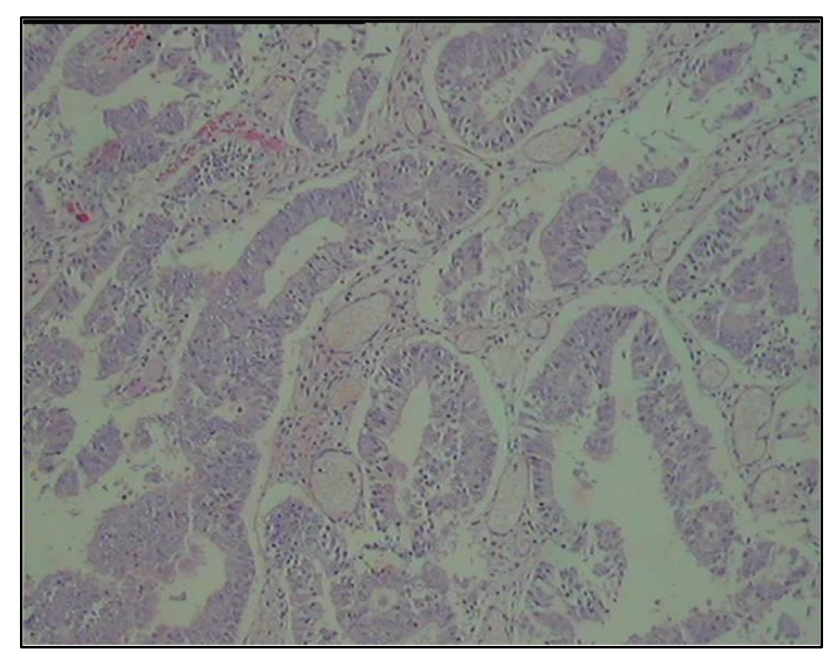

Figure 1: Endometrioid carcinoma.

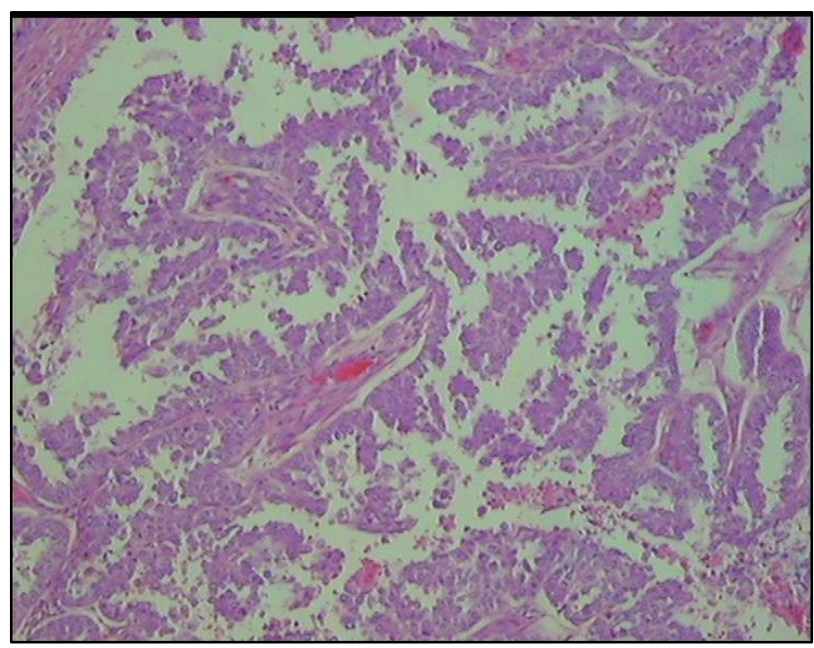

Figure 2: Nonendometrioid carcinoma.
Obesity is an important risk factor for endometrial carcinoma, in our sample of 90 patients most of the patients was obese, and this risk factor was statistically processed and presented.

Body Mass Index (BMI) is height-weight indicator of nutritional status. Analysing the body mass index, number of patients who had a BMI $<30 \mathrm{~kg} / \mathrm{m}^{2}$ was 36 (40\%), which is not considered obese, according to the World Health Organization and the International association for the study of obesity. BMI $>30 \mathrm{~kg} / \mathrm{m}^{2}$ was observed in $54(60 \%)$ patients, and it is considered obesity. Endometrioid carcinoma had 16 (45\%) patients with a BMI $<30 \mathrm{~kg} / \mathrm{m}^{2}$, and the Non-endometrioid carcinoma had $20(55 \%)$ patients. $38(70 \%)$ patients with a BMI $>30 \mathrm{~kg} / \mathrm{m}^{2}$ had endometrioid carcinoma, and 16 patients $(30 \%)$ had non-endometrioid carcinoma.

Table 1: Division of endometrioid and endometrioid carcinoma in relation to $\mathrm{BMI}$.

\begin{tabular}{|lll|l|}
\hline $\begin{array}{l}\text { Body mass } \\
\text { index }\end{array}$ & $\begin{array}{l}\text { Endometrioid } \\
\text { carcinoma }\end{array}$ & $\begin{array}{l}\text { Non- } \\
\text { endometrioid } \\
\text { carcinoma }\end{array}$ & Total \\
\hline $\begin{array}{l}\mathrm{BMI}<30 \\
\mathrm{~kg} / \mathrm{m}^{2}\end{array}$ & $16(45 \%)$ & $20(55 \%)$ & $36(40 \%)$ \\
\hline $\begin{array}{l}\mathrm{BMI}>30 \\
\mathrm{~kg} / \mathrm{m}^{2}\end{array}$ & $38(70 \%)$ & $16(30 \%)$ & $54(60 \%)$ \\
\hline
\end{tabular}

\section{DISCUSSION}

Of the total number of diseased patients 65 patients $(73 \%)$ had endometrioid carcinoma type 1 and 25 patients (27\%) had a nonendometriod cancer type 2 obesity, as well as estrogen replacement therapy, is well-defined risk factor for endometrial cancer, with the reported relative risk in the range of 2 to $10 .^{1-3}$ The risk can be explained by the presence of increased estrogen as a result of peripheral aromatization of androgens to estrogens in adipose tissue and reduced binding globulin concentration of sex hormones in obese women. ${ }^{4}$ The risk of endometrial cancer is correlated with the total intake of calories, total protein intake, frequency of consumption of eggs, meat, milk, fat and oil. These nutritional factors as well as reduced energy consumption and physical activity, coupled with seating lifestyle are the main determinants of obesity, which is an identified risk factor. The independent contribution of specific dietary factors on the risk of endometrial cancer is not clearly established. ${ }^{3,5}$ Recent studies suggest that activity reduces the risk of endometrial cancer regardless of body weight. ${ }^{1}$ Obesity is the strongest risk factor for the development of endometrial cancer due to the mechanism of increased exposure to estrogen. Consequently, the link between obesity and endometrial cancer is stronger in cases of tumor type 1, typical estrogen-dependent tumors. Pathophysiological mechanism by which obesity increases the risk of the disease is based on an increased level of serum estrogens without opposing (missing) progesterone. Increased levels of endogenous estrogens produced as a result of the increased conversion of 
androstenedione to estrone in adipose tissue and reduced levels of sex hormone binding globulin (SHBG). In the absence of progesterone, unopposed estrogen stimulates cell proliferation, which causes endometrial hyperplasia and a potential cancer development. Obesity has a high association with that fact. Brinton et al showed that BMI greater than $32 \mathrm{~kg} / \mathrm{m}^{2}$ increase risk of disease four times, a BMI greater than $35 \mathrm{~kg} / \mathrm{m}^{2}$ increase the risk six times. Special attention is given to women with android obesity or accumulation of body fat in the abdomen and chest. It was observed that with them the level of peripheral estrogen caused significantly higher than in women with gynaecoid type of obesity or with a special accumulation of fatty tissue in the area of the hips, thighs and glutes. Parazzini and colleagues have shown that the risk of developing endometrial cancer, in obese women nine times higher than in non-obese. It was also observed that fluctuations in body weight, using inadequate dietary regime, does not reduce the risk of disease, and that the risk increases by returning to a state of obesity. ${ }^{6}$ In our study, 36 patients $(40 \%)$ who had a BMI (body mass index - BMI) $<30 \mathrm{~kg} / \mathrm{m}^{2}$ and 54 patients $(60 \%)$ who had a body mass index $30 \mathrm{~kg} / \mathrm{m}^{2}$. In non-obese group 16 patients $(45 \%)$ had endometriod carcinoma - type 1 , and twenty patients $(55 \%)$ non-endometrioid carcinoma - type second. In the group of obese patients $38(70 \%)$ had endometrioid carcinoma - type 1:16 patients $(30 \%)$ nonendometrioid carcinoma - the second type, the results are in line with the global results. In obese patients with overweight from 9.5 to $23 \mathrm{~kg}$ develops three times more often endometrial cancer compared to women of normal weight, those over $23 \mathrm{~kg}$ overweight frequency of occurrence increases tenfold. The main cause of the increased ekstraglandular conversion of androstenedione to estrone and of DHEA, particularly in the subcutaneous adipose tissue. ${ }^{4}$ Hyperestrogenemia can lead to proliferation of the endometrium, endometrial hyperplasia, and in some cases of endometrial carcinoma.

\section{CONCLUSION}

Endometrioid endometrial cancer is a common type of cancer in relation to non-endometrioid endometrial carcinoma. Obesity is the strongest risk factor for the development of endometrial cancer due to the mechanism of increased exposure to non-opposed estrogen. Consequently, the link between obesity and endometrial cancer is stronger in cases of tumor type 1, typical estrogen-dependent tumors.
Patients suffering from endometrial cancer often have an increased body mass index $(\mathrm{BMI})>30 \mathrm{~kg} / \mathrm{m}^{2}$. Non-obese patients often suffer from non-endometrioid cancer, while obese patients often suffer from endometrioid carcinoma.

\section{Funding: No funding sources \\ Conflict of interest: None declared}

Ethical approval: The study was approved by the Institutional Ethics Committee

\section{REFERENCES}

1. Enriori CL, Reforzo-Membrives J. Peripheral aromatization as a risk factor for breast and endometrial cancer in postmenopausal women: a review. Gynecol Oncol. 1984;17:1-21.

2. Parazzini F, Franceschi S, La Vecchia C, Chatenoud, L, Di Cintio E. Thae epidemiology of female genital tract cancers. Int J Gynecol Cancer. 1997;7:169-81.

3. Parazzini F, La Vecchia C, Bocciolone L, Franceschi S. The epidemiology of endometrial cancer. Gynecol Oncol. 1991;41:1-16.

4. Brinton LA, Berman ML, Mortel R, Twiggs LB, Barrett RJ, Wilbanks GD, et al. Reproductive, menstrual, and medical risk factors for endometrial cancer: results from a case-control study. Am J Obstet Gynecol. 1992;167:1317-25.

5. MollUM, Chalas E, Auguste M, Meaney D, Chumas J. Uterine papillary serous carcinoma evolves via a p53-driven pathway. Hum Pathol. 1996;27:1295300.

6. Saegusa M, Kamata Y, Isono M, Okayasu I. Bcl-2 expression is correlated with a low apoptotic index and associated with progesterone receptor immunoreactivity in endometrial carcinomas. J Pathol. 1996;180:275-82.

7. Shiozawa T, Konishi I. Early endometrial carcinoma: clinicopathology, hormonal aspects, molecular genetics, diagnosis and treatment. The International Journal of Clinical Oncology. 2006;11:13-21.

8. Sankaranarayanan R, Ferley J. Worlwide burden of gynecological cancer: the size of problem. Best Pract Res Clin Obstet Gynecol. 2006;20:207-25.

9. Ryan AJ, Susil B, Jobling TW, Oehler MK. Endometrial cancer. Cell Tissue Research. 2005;322:53-61.

Cite this article as: Suskic A, Suskic SH, Opric D, Maksimovic S. Obesity as a significant risk factor for endometrial cancer. Int J Reprod Contracept Obstet Gynecol 2016;5:2949-51. 